\title{
TP53 codon 72 polymorphism may predict early tumour progression in paediatric pilocytic astrocytoma
}

\author{
Samantha Mascelli' ${ }^{1}$, Paolo Nozza², David T.W. Jones ${ }^{3}$, Carole Colin ${ }^{4}$, Angela \\ Pistorio ${ }^{5}$, Claudia Milanaccio ${ }^{1}$, Marcello Ravegnani ${ }^{1}$, Alessandro Consales ${ }^{1}$, Olaf \\ Witt ${ }^{6}$, Giovanni Morana7, Armando Cama ${ }^{1}$, Valeria Capra ${ }^{1}$, Roberto Biassoni ${ }^{8}$, Stefan \\ M. Pfister ${ }^{3,6}$, Dominique Figarella-Branger ${ }^{4,9}$, Maria Luisa Garrè ${ }^{10}$, Alessandro Raso ${ }^{1}$ \\ ${ }^{1}$ Dipartimento Testa, Collo e Neuroscienze, Istituto Giannina Gaslini, 16147 Genoa, Italy \\ ${ }^{2}$ UOC Anatomia Patologica, Istituto Giannina Gaslini, 16147 Genoa, Italy \\ ${ }^{3}$ Division of Paediatric Neurooncology, German Cancer Research Center (DKFZ), Heidelberg 69120, Germany \\ ${ }^{4}$ CRO2 UMR_S911, Inserm, Aix-Marseille Université, 13385 Marseille, France \\ ${ }^{5}$ Epidemiologia, Biostatistica e Comitati, Istituto Giannina Gaslini, 16147 Genoa, Italy \\ ${ }^{6}$ Department of Paediatric Oncology, Haematology and Immunology, University of Heidelberg, Heidelberg, 69120 Heidelberg, \\ Germany \\ ${ }^{7}$ Neuroradiologia Istituto Giannina Gaslini, 16147 Genoa, Italy \\ ${ }^{8}$ Laboratory Molecular Medicine, Translational Medicine Department, Istituto Giannina Gaslini, 16147 Genoa, Italy \\ ${ }^{9}$ APHM, Hôpital de la Timone, Service d'Anatomie Pathologique et de Neuropathologie, 13385 Marseille, France \\ ${ }^{10}$ Centro di Neuro-Oncologia, Istituto Giannina Gaslini, 16147 Genoa, Italy
}

Correspondence to: Samantha Mascelli, email: SamanthaMascelli@gaslini.org

Keywords: low-grade gliomas, polymorphism, pilocytic astrocytoma, paediatric, TP53

Received: March 25, 2016

Accepted: May 10, 2016

Published: June 25, 2016

\section{ABSTRACT}

Pilocytic astrocytoma and ganglioglioma may occur in inaccessible or surgically difficult areas. In case of incomplete resection, the availability of biological predictors of tumour progression could be particularly important. To this end, an analysis of p53 codon 72 polymorphism and assessment of its role as prognostic marker were performed.

The status of the p53 Arg72Pro polymorphism was evaluated by pyrosequencing method in a multicenter cohort of 170 paediatric patients. Genotype/phenotype associations were investigated either by means of bivariate or multivariate analyses.

In the partially resected pilocytic astrocytomas, the Arg/Arg variant predicts early tumour progression (median survival time: $\mathbf{2 3 . 1}$ months) and is associated with poor event-free survival ( $p$ value $=\mathbf{0 . 0 0 0 9}$ ). This finding remains true also in case of adjuvant therapies, with a 5-year event-free survival of $\mathbf{3 0 . 6 \%}$ for cases with Arg/Arg variant vs. $\mathbf{7 8 . 7 \%}$ for those with other genotypes. There is no association between ganglioglioma and the polymorphism.

The assessment of Arg/Arg variant could improve the management of pilocytic astrocytoma. TP53 codon 72 analysis could distinguish low-risk cases, in which surgery could be conservative, from high-risk cases needing an aggressive surgery plan.

\section{INTRODUCTION}

Genetic studies suggest that some functional single-nucleotide polymorphisms (SNPs) involved in cell death control and DNA-repair mechanisms influence the prognosis of sporadic tumours. In other words, SNPs could act on either the regulation of apoptotic potential or the maintenance of genomic stability through different DNA repair pathways $[1,2]$. An example is the $\mathrm{p} 53$ protein, which responds to a variety of cellular stresses performing multiple functions involved in cell cycle control [3]. Notably, p53 function is perturbed by DNA sequence variations, such as 
SNPs. To date, several TP53 SNPs have been characterized, many of them being localized in non-coding regions of the gene [4]. Among those found in the TP53 coding region, the variant at codon 72 (rs1042522) is the most extensively studied. This consists of a $\mathrm{G} / \mathrm{C}$ variation resulting in a nonconservative change of an arginine $(\mathrm{R})$ to a proline $(\mathrm{P})$ in exon 4 (Arg72Pro;). Residue 72 is located within a prolinerich region and may affect the structure of the putative $\mathrm{SH} 3-$ binding motif (PXXP), one of the p53 DNA-binding motifs responsible for the pro-apoptotic function of the protein [3]. The Arg72 isoform is more efficient in inducing apoptosis, while the Pro 72 variant activates transcriptionally several p53-dependent genes involved in DNA-repair and cell-cycle arrest [5]. A possible association between TP53 codon 72 variants and cancer progression has been reported for several tumour types [6-15].

Low-grade gliomas (LGGs) and glioneuronal tumours are the most common brain tumours in childhood and adolescence. Among them, pilocytic astrocytomas (PAs) are the predominant pathological subtype, followed by mixed neuronal and glial tumours, such as gangliogliomas (GGs) and desmoplastic infantile gangliogliomas (DIGs). LGGs generally growth slowly and show favourable outcome, although $10-20 \%$ of children develop progressive disease or recur [16-18]. The extent of tumour resection remains the main prognostic factor: after complete surgical resection 10 - year overall survival rates are $90 \%$ or higher [19]. Conversely, whenever complete resection is not achieved, either because of anatomical location or metastatic disease, adjuvant therapies, including further surgery, chemotherapy and radiation, could be necessary [17, 20-22]. As yet, neither biological predictors nor the temporal window critical for early detection of progression are known. These tumours may progress early, within 2 years from diagnosis or become stable for more than 5 years. As a consequence, there is a clinical need to find molecular predictors for early progression in paediatric LGGs and glioneuronal tumours as well as for long-term outcome. Despite TP53 inactivation in several tumours, [23-25] somatic mutations are rare in paediatric LGGs [26-28]. It is noteworthy, however, that few studies addressed the role of Arg72Pro SNP in glial tumours: most of them included high grade tumours or adult cases and yield inconsistent results [6, 15, 29-30].

Here, we focused on the p53 Arg72Pro status in a multicenter cohort of paediatric PAs and WHO grade I mixed neuronal and glial tumours, testing its role both as risk factor and marker of early progression.

\section{RESULTS}

\section{p53 codon 72 distribution in the cohort}

The genetic analysis of p53 codon 72 was performed on 170 tumours from patients affected by PAs and mixed neuronal and glial tumours (GGs and DIGs). The genotype distribution of the SNP was the following: Arg/Arg 48.2\% $(n=82) ;$ Arg/Pro 42.4\% $(n=72) ;$ Pro/Pro 9.4\% $(n=16)$, and are reported in Table 1 . The distribution of both genotype and allele frequencies in all patients met the Hardy-Weinberg Equilibrium.

Congruent results were obtained from the analysis on somatic tumour DNAs and germ-line DNAs from matched blood samples: no difference in p53 codon 72 variants was seen between isogenic samples. The bivariate analyses through cases stratification by the main histological and clinical features revealed no differences in the distribution of genotype and allele frequencies. Similarly, no relationship was found with KIAA1549$B R A F$ gene-fusion and $B R A F$ mutations (Table 1).

\section{Arg/Arg72 p53 variant correlates with poor EFS for partially resected PAs}

The Incidence Rates (IR) with selected clinical features were evaluated for PAs and mixed neuronal and glial tumours separately. The analysis on PAs $(n=138)$ did not show any association between p53 codon 72 SNP distribution and EFS when extent of resection was not taken into account, as shown in supplementary Table 1.

When only partially or sub-totally resected (STR) tumours were considered $(n=46)$, the incidence of progressions was significantly higher in tumours harbouring Arg/Arg variant $(14.77 \times 1000 p-m)$ compared to those harbouring Arg/Pro or Pro/Pro variants $(3.78 \times 1000$ $p-m)$ in the dominant model $(p$ value $=0.031)($ Table 2$)$. Patients with Arg/Arg genotype showed a significantly worse EFS than those with a Proline variant, with a 5-year EFS of $30.6 \%$ vs. $78.7 \%$, respectively (Figure 1A). The median survival time (MST) of patients with PA who underwent STR was 23.1 months for the Arg/ Arg genotype, while it was statistically not observable for the Arg/Pro or Pro/Pro genotype grouping (Figure 1A). Likewise, in presence of adjuvant therapies $(n=26), \mathrm{Arg} /$ Arg genotype showed significantly shorter EFS compared with the other genotypes ( $p$ value $=0.018)($ Figure 1B).

Furthermore, gender-stratified incidence rates differed significantly $(p$ value $=0.012)$ : female patients $(15.18 \times 1000 p-m)$ had a worse EFS than male patients $(2.48 \times 1000 \mathrm{p}-\mathrm{m})$ (Table 2$)$. Regarding age and tumour site of lesion at diagnosis, no difference in EFS was observed ( $p$ value $=0.30$ and $p$ value $=0.41$, respectively) .

Multivariate analysis using Poisson regression model identified Arg72Pro SNP and gender associated with risk of progression in patients with partial tumour resection. An increased risk for progression was observed in Arg/Arg genotype (adjusted IRR $=6.4,95 \%$ CI: $2.1-19.3 ; p$ value $=$ 0.0009 ), and in female patients (adjusted IRR $=9.4,95 \%$ CI: $2.6-34.3 ; p$ value $=0.0001)($ Table 3$)$. The remaining factors tested in the model were not associated with a higher risk disease progression: age at diagnosis ( $p$ value $=$ $0.76)$, site of lesion ( $p$ value $=0.36$ ), additional treatments $(p$ value $=0.72)$. 
Table 1: Distribution of p53 (Arg72Pro) genetic variant among 170 cases and its association with clinical and genetic characteristics

\begin{tabular}{|c|c|c|c|c|c|c|c|c|c|}
\hline & & \multicolumn{5}{|c|}{ No. $(\%)$ per genotype } & \multicolumn{3}{|c|}{ No. $(\%)$ per allele } \\
\hline & & No. & Arg/Arg* & Arg/Pro* & Pro/Pro* & $p$ value & Arg* & Pro* & $p$ value \\
\hline & Patients & 170 & $82(48.2)$ & $72(42.4)$ & $16(9.4)$ & $0.38^{\mathrm{a}}$ & $236(69.4)$ & $104(30.6)$ & $0.17^{\mathrm{a}}$ \\
\hline & Controls & 192 & $104(54.2)$ & $76(39.6)$ & $12(6.2)$ & & $284(74.0)$ & $100(26.0)$ & \\
\hline \multirow[t]{2}{*}{ Patient Gender: } & male & 88 & $44(50.0)$ & $40(45.5)$ & $4(4.5)$ & $0.08^{\mathrm{a}}$ & $128(72.7)$ & $48(27.3)$ & $0.17^{\mathrm{a}}$ \\
\hline & female & 82 & $38(46.3)$ & $32(39.0)$ & $12(14.6)$ & & $108(65.9)$ & $56(34.1)$ & \\
\hline \multirow[t]{2}{*}{ Histology: } & $\begin{array}{l}\text { Mixed neuronal } \\
\text { and glial tumors }\end{array}$ & 31 & $16(51.6)$ & $11(35.5)$ & $4(13)$ & $0.59^{\mathrm{b}}$ & $43(69.3)$ & $19(30.6)$ & $0.99^{\mathrm{a}}$ \\
\hline & $\begin{array}{l}\text { Pilocytic } \\
\text { Astrocytoma }\end{array}$ & 139 & $66(47.5)$ & $61(43.9)$ & $12(8.6)$ & & $193(69.4)$ & $85(30.6)$ & \\
\hline \multirow[t]{2}{*}{ Age at diagnosis: } & $\leq 24$ months & 24 & $16(66.7)$ & $5(20.8)$ & $3(12.5)$ & $0.05^{\mathrm{b}}$ & $37(77.1)$ & $11(22.9)$ & $0.21^{\mathrm{a}}$ \\
\hline & $>24$ months & 146 & $66(45.2)$ & $67(45.9)$ & $13(8.9)$ & & $199(68.2)$ & $93(31.8)$ & \\
\hline \multirow[t]{2}{*}{ Brain lesion site: } & Supratentorial & 65 & $34(52.3)$ & $24(36.9)$ & $7(10.8)$ & $0.52^{\mathrm{a}}$ & $92(70.8)$ & $38(29.2)$ & $0.67^{\mathrm{a}}$ \\
\hline & Infratentorial & 105 & $48(45.7)$ & $48(45.7)$ & $9(8.6)$ & & $144(68.6)$ & $66(31.4)$ & \\
\hline \multirow[t]{2}{*}{ EFS: } & progression & 26 & $13(50.0)$ & $10(38.5)$ & $3(11.5)$ & $0.82^{\mathrm{b}}$ & $36(69.2)$ & $16(30.8)$ & $0.98^{\mathrm{a}}$ \\
\hline & stable disease & 144 & $69(47.9)$ & $62(43.1)$ & $13(9.0)$ & & $200(69.4)$ & $88(30.6)$ & \\
\hline \multirow[t]{2}{*}{ BRAF,V600E } & mutation & 19 & $9(47.4)$ & $6(31.6)$ & $4(21.0)$ & $0.27^{\mathrm{b}}$ & $24(63.2)$ & $14(36.8)$ & $0.37^{\mathrm{a}}$ \\
\hline & Wild-type & 115 & $57(49.6)$ & $48(41.7)$ & $10(8.7)$ & & $16(70.4)$ & $68(29.6)$ & \\
\hline \multirow[t]{2}{*}{$\begin{array}{l}\text { KIAA1549-BRAF } \\
\text { gene fusion }\end{array}$} & Present & 84 & $42(50.0)$ & $34(40.5)$ & $8(9.5)$ & $0.76^{\mathrm{b}}$ & $118(70.2)$ & $50(29.8)$ & $0.97^{\mathrm{a}}$ \\
\hline & Absent & 40 & $21(52.5)$ & $14(35.0)$ & $5(12.5)$ & & $56(70.0)$ & $24(30.0)$ & \\
\hline
\end{tabular}

*p53 codon 72 ; ${ }^{\mathrm{a}} P$ values: Pearson $\chi^{2}$ test; ${ }^{\mathrm{b}} P$ values: Fisher's Exact test.

A

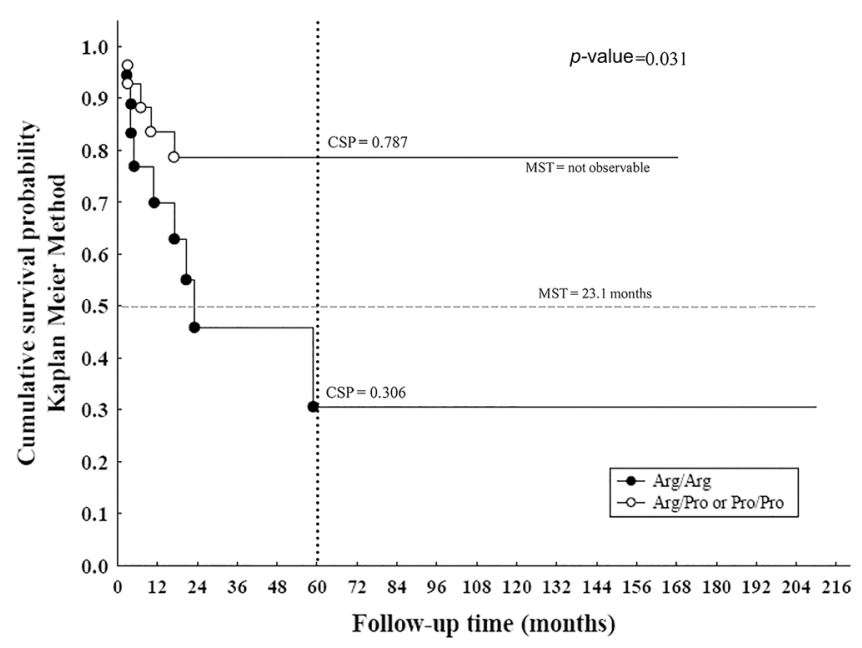

B

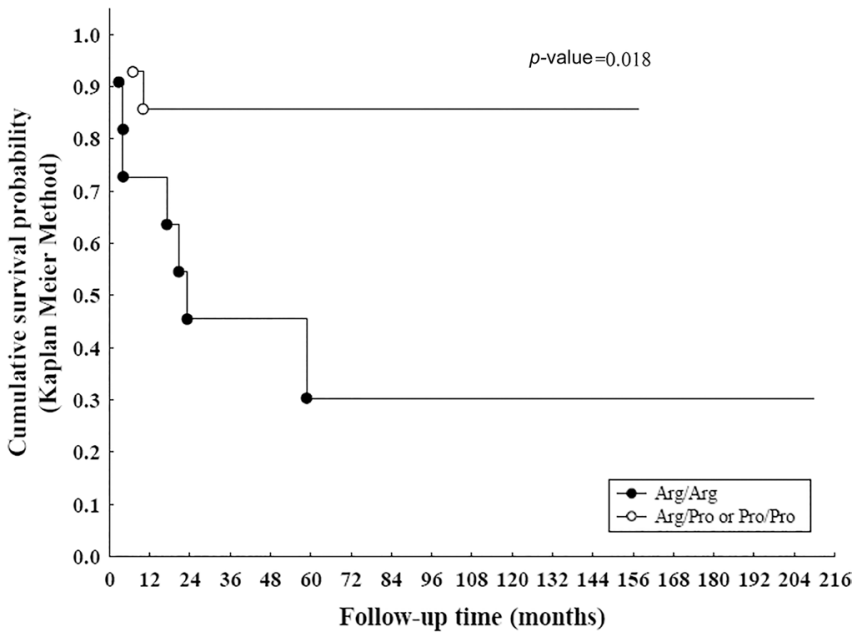

Figure 1: Survival curves of PAs in case of incomplete resection. (A) Kaplan-Meier survival curve of EFS for only PAs $(n=46)$ showed shorter survival in cases with Arg/Arg variant with a cumulative survival probability (CSP) of $30.6 \%$ respect to $78.7 \%$ in the other genotypes containing Proline and, with a MST of 23.1 months, a predictor of early progression events (Log-rank test, $p$ value $=0.031)$; (B) EFS for PA with additional treatments $(n=26)$ showed shorter survival in presence of Arg/Arg variant (Log rank test, $p$ value $=0.018)$ compared with the other genotypes. 
Table 2: Number of deaths/disease progression (and percentage) and EFS: IR for progression events in patients undergoing to STR with PA $(n=46)(n=14 / 46 ; 30.4 \%)$, IR: $7.3 \times 1000$ p-m (95\% CI: $4.3-12.2)$

\begin{tabular}{|c|c|c|c|c|}
\hline & & $\begin{array}{l}\text { No. of disease } \\
\text { progression or } \\
\text { deaths }(\%)\end{array}$ & $\begin{array}{c}\text { EFS } \\
\text { IR } \times 1000 \mathrm{p}-\mathrm{m} \\
(95 \% \mathrm{CI})\end{array}$ & $\begin{array}{c}p \text { value } \\
\text { Log-Rank }\end{array}$ \\
\hline \multirow[t]{2}{*}{ Gender: } & Male $(n=23)$ & $3(13.0 \%)$ & $2.485(0.8-7.7)$ & ${ }^{*} 0.012$ \\
\hline & Female $(n=23)$ & $11(47.8 \%)$ & $15.179(8.4-27.4)$ & \\
\hline \multirow[t]{2}{*}{ Age at diagnosis: } & $\leq 24$ months $(n=8)$ & $4(50 \%)$ & $10.352(3.9-27.6)$ & 0.30 \\
\hline & $>24$ months $(n=38)$ & $10(26.3 \%)$ & $6.469(3.5-12.0)$ & \\
\hline \multirow[t]{2}{*}{ Site of lesion: } & Supratentorial $(n=21)$ & $8(38.1 \%)$ & $9.401(4.7-18.8)$ & 0.41 \\
\hline & Infratentorial $(n=25)$ & $6(24.0 \%)$ & $5.550(2.5-12.4)$ & \\
\hline \multirow[t]{2}{*}{ Additional treatments: } & Yes $(n=25)$ & $9(36 \%)$ & $6.800(3.5-13.1)$ & 0.87 \\
\hline & No $(n=21)$ & $5(23.8 \%)$ & $8.214(3.4-19.7)$ & \\
\hline \multirow[t]{2}{*}{ p53 Arg72Pro(dominant model): } & $\operatorname{Arg} / \operatorname{Arg}(n=18)$ & $9(50.0 \%)$ & $14.769(7.7-28.4)$ & ${ }^{*} 0.031$ \\
\hline & $\operatorname{Arg} / \operatorname{Pro}$ or Pro/Pro $(n=28)$ & $5(17.9 \%)$ & $3.780(1.6-9.1)$ & \\
\hline
\end{tabular}

IR $\times 1000$ p-m (95\% CI): Incidence Rate $\times 1000$ person-months (95\% Confidence Intervals); ${ }^{*}$ significant $p$ values

Table 3: Best fitted Poisson Regression model

\begin{tabular}{|c|c|c|c|c|}
\hline $\begin{array}{c}\text { Patients } \\
\text { (No. of events }=14 / 46 ; 30.4 \%)\end{array}$ & & Hazard Ratio (HR) ${ }^{a}$ & $95 \% \mathrm{CI}$ & $p$ value \\
\hline Gender: & Female versus Male & 9.4 & $2.6-34.3$ & ${ }^{*} 0.0001$ \\
\hline p53 Arg72Pro (dominant model): & Arg/Arg versus Arg/Pro or Pro/Pro & 6.4 & $2.1-19.3$ & *0.0009 \\
\hline
\end{tabular}

EFS; time variable measured from diagnosis to date of progression or death (months) in patients undergoing to STR with PA $(n=46)$.

*significant $p$ values.

Moreover, incidence rates evaluated only in mixed neuronal and glial tumours did not show any association with the TP53 codon 72 SNP ( Supplementary Table 2).

\section{DISCUSSION}

PAs and mixed neuronal and glial tumours occurring in surgically non amenable sites pose several challenges to paediatric oncologists. Their significant morbidity is partly related to therapy side effects. Thus, it is extremely important to tailor the therapies more precisely.

We focused on the p53 Arg72Pro status in a multicenter cohort of PAs, GGs, and DIGs, testing its role both as a risk factor and biological marker of early progression. The current study is focused upon a welldefined series of paediatric cases arising in the EuropeanCaucasian population, recruited over an 18-year period.

The biological value of p53 Arg72Pro variant in cancer risk and progression is extremely controversial $[6,7,31]$. A possible explanation could be found in population genetics. Indeed, a meta-regression study suggested that ethnicity, as well as histotyping, anatomical sites and genotyping method, are responsible for most of the heterogeneity observed [32]. Recently, TP53 polymorphism has been investigated in adult high-grade gliomas [33]. An association between the Arg72 variant has also been reported to increase risk of developing, lymphocytic leukaemia and gastric and skin cancer $[8,34]$.

Herein, a cohort of European-Caucasian patients has been analyzed, since sharp ethnic differences were previously observed for Arg72Pro SNP. In fact, the Arg72 variant was found more prevalent in EuropeanCaucasians, whereas the Pro72 variant was predominant in Chinese and African-Americans. A significant NorthSouth gradient for the Arg allele was found, with an increase in allele frequency in association with distance from the equatorial plate [35].

Our results showed no significant difference in the genotype and allele frequencies between tumours and controls, and no significant association when tumour samples were stratified by neuropathological features (Table 1). Moreover, no difference was seen at p53 codon 72 between tumour and isogenic blood, indicating that such analysis can be carried out from either material.

Intriguingly, the survival analysis showed a statistically significant difference in EFS for European- 
Caucasian patients with PAs for whom a gross total resection was not achieved: EFS was worse for patients with PA carrying Arg/Arg variant than the other genotypes in a dominant model (Figure 1A), indicating a prognostic impact on early progression events. Interestingly, Arg variant seems to favour inactivation of p73-dependent apoptosis in tumours with mutant p53 [4, 5, 36]. Since dysfunctional missense TP53 mutations are rare in childhood LGGs, the codon 72 SNP probably influences clinical course in combination with clinical variables or other genetic variations.

No association with TP53 polymorphism was found in mixed neuronal and glial tumours (Supplementary Table 2). Thus, independently from resection type and site of lesion, TP53 codon 72 SNP is not a EFS predictor marker. A deeper analysis was not possible because of the small sample size of each group.

Conversely, p53 Arg/Arg72 variant reliably predicts early progression in partially resected PAs (Table 2), also independent of the adjuvant treatment (Figure 1B). Thus, this polymorphism may even modulate individual response to therapy $[6,7]$. Radiotherapy and chemotherapy cause DNA damage. This SNP, is essential for p53-induced cell cycle arrest, and, in presence of extensive DNA damage, promote the irreversible growth arrest (senescence) or induce apoptosis [7]. Glioma cells choose tumour regulation growth through via senescence [37]: our findings suggest that, in some way, the presence of Arg72 in homozygous is an adverse prognostic factor in case of tumour residual.

The relation of Arg/Arg variant to EFS has been verified in multivariate analysis (Table 3). Noteworthy, as previously reported [19], gender seems to be an independent risk factor for PA progression (Table 2, 3).

In summary, we highlighted the role of p53 Arg/ Arg72 variant as a predictor for early progression in partially resected PAs. Further validation in another cohort is needed to include such a marker in future trials by guiding future p53-activation therapy. This result could significantly change the patient management, distinguishing low risk cases in which surgery could be conservative, from cases for whom a more aggressive surgery plan could be appropriate. Thus, the inclusion of this SNP analysis into molecular screening might influence the choice of adjuvant therapies or plan proper followup. The genetic test could be easily performed on blood samples, and would be a quick, non-invasive and cheap method.

\section{MATERIALS AND METHODS}

\section{Participants}

The study cohort consisted of 170 tumours from patients of European-Caucasian ethnicity affected by pilocytic astrocytomas (PAs) and mixed neuronal and glial tumours (GGs and DIGs), including 66 cases treated at the Giannina Gaslini Institute, Genoa - Italy, 20 cases from the Marseille series (retrieved from the Assistance PubliqueHôpitaux de Marseille -AP-HM tumor bank, Franceauthorization number AC-2013-1786) and 84 cases from the Heidelberg cohort (German Cancer Research Centre -DKFZ-, Heidelberg, Germany). For all cases clinical data were available. Patients' median age at diagnosis was 7.0 years (range 4.9 months -16.6 years) and all CNS sites were affected. Median follow-up time was 7.4 years \pm 4.2 SD. Surgical treatment consisted of 100 (63.3\%) complete and $58(36.7 \%)$ partial removals; no information available in 12 cases. Progression event occurred in 25 cases $(14.8 \%)$, whose 17 were PA and 8 were mixed neuronal and glial tumours. In the presence of a residual tumour tissue, an observation period or the administration of adjuvant therapies, consisting of radiotherapy and/or chemotherapy, were offered according to the International Society of Paediatric Oncology protocol for lowgrade gliomas (SIOP-LGG) [38]. Clinic-pathological characteristics are listed in Supplementary Table 3, and summarized in a flow chart, as shown in Figure 2.

For the mutational screening of TP53 codon 72 SNP, we analyzed DNA from 86 cases out of the Italian and French patients (55 PAs and 31 mixed neuronal and glial tumours): only samples with a tumour cell content of at least $80 \%$ were used for molecular screening. Conversely, genetic data of 84 PAs were directly collected from the Heidelberg files. Genetic analysis of this cohort has been described previously [39]. Furthermore, peripheral matched blood DNA from 66 patients and from 192 healthy children (median age 10 years) was also investigated.

Correlation analysis between TP53 codon 72 variant and $B R A F$ alteration were performed using previously described $B R A F$ genetic data [39-41].

Written informed consent was obtained from all the patients' parents or guardians, as well as for the controls.

The experiments described comply with the current laws of the countries in which they were performed. The local Ethics Committee for human studies approved the research according to Institutional guidelines.

\section{TP53 codon 72 pyrosequencing assay}

Genomic DNA was isolated by using the GenElute Mammalian Genomic DNA Miniprep kit (Sigma, St. Louis, MO) from both frozen sections of tumour tissue samples and peripheral blood, according to the manufacturer's protocol. Primers for TP53 codon 72 variant (rs1042522) were designed following the manufacturer's protocols for pyrosequencing. The locus-specific codon 72 of TP53 was amplified using 200 nM of TP53-F-5'-GCTGTCCCCGGACGATATT-3' and TP53-R-5'-GCCGGTGTAGGAGCTGCTG-3' primers, respectively. The forward primer contained biotin at the $5^{\prime}$ position. Amplification was carried out in a 25 micro-litre 
final volume reaction using $20 \mathrm{ng}$ of genomic DNA. Thermal profile used was 2 minutes $94^{\circ} \mathrm{C}$, and 35 cycles with 30 seconds at $94^{\circ} \mathrm{C}, 30$ seconds at $58^{\circ} \mathrm{C}$, and 30 seconds at $72^{\circ} \mathrm{C}$, followed by 7 minutes at $72^{\circ} \mathrm{C}$.

All pyrosequencing reactions were performed with a reverse sequencing primer 5'-GGTGCAGGGGCC ACG-3' used to detect a sequence like C/GGGGGAGCAGC CTCTGGCATTCTGGG as previously described [42].

\section{Statistical analysis}

Descriptive statistics were reported in terms of absolute frequencies or percentages for qualitative data, while in terms of medians, first and third quartiles (1st-3rd q), standard deviations (SDs), minimum, and maximum values for continuous quantitative data. Deviation from Hardy-Weinberg Equilibrium of Arg72Pro SNP was determined using a goodness of fit chi-square $\left(\chi^{2}\right)$ test. Pearson's chi-square test (or Fisher's Exact test in case of expected frequencies lower than 5) was used to compare the distribution of genotype and allele frequencies among patients and controls.

Considering the clinical course of PAs and of mixed neuronal and glial tumours, EFS rather than Overall
Survival (OS), was chosen as the primary end-point. Furthermore, since only two events of death were present among the cohort, data was considered not sufficiently informative to even perform OS analysis. EFS was defined as the time from diagnosis to the date of progression or date of death, and all patients surviving at the time of analyses were censored at the date of last contact.

IR of death or disease progression were calculated and reported with their 95\% Confidence Intervals (95\% CI). Survival curves were drawn to assess disease-free survival and time to the event was expressed as personmonths. Survival curves were constructed according to the Kaplan-Meier method and compared by the log-rank test.

Finally, a Poisson regression model was performed in order to evaluate the role of clinic-pathological and genetic variables in influencing hazard ratios (HR). Statistically significant variables in the bivariate analysis or clinically important variables were subsequently included in the multivariate analysis. The following variables were considered into the saturated model: gender (female $v$ s. male), age at diagnosis $(\leq 24$ months $v s .>24$ months), site of lesion (supratentorial vs. infratentorial), additional treatments (yes vs. no) and p53 codon 72 SNP (Arg/Arg vs. Arg/Pro or Pro/Pro).

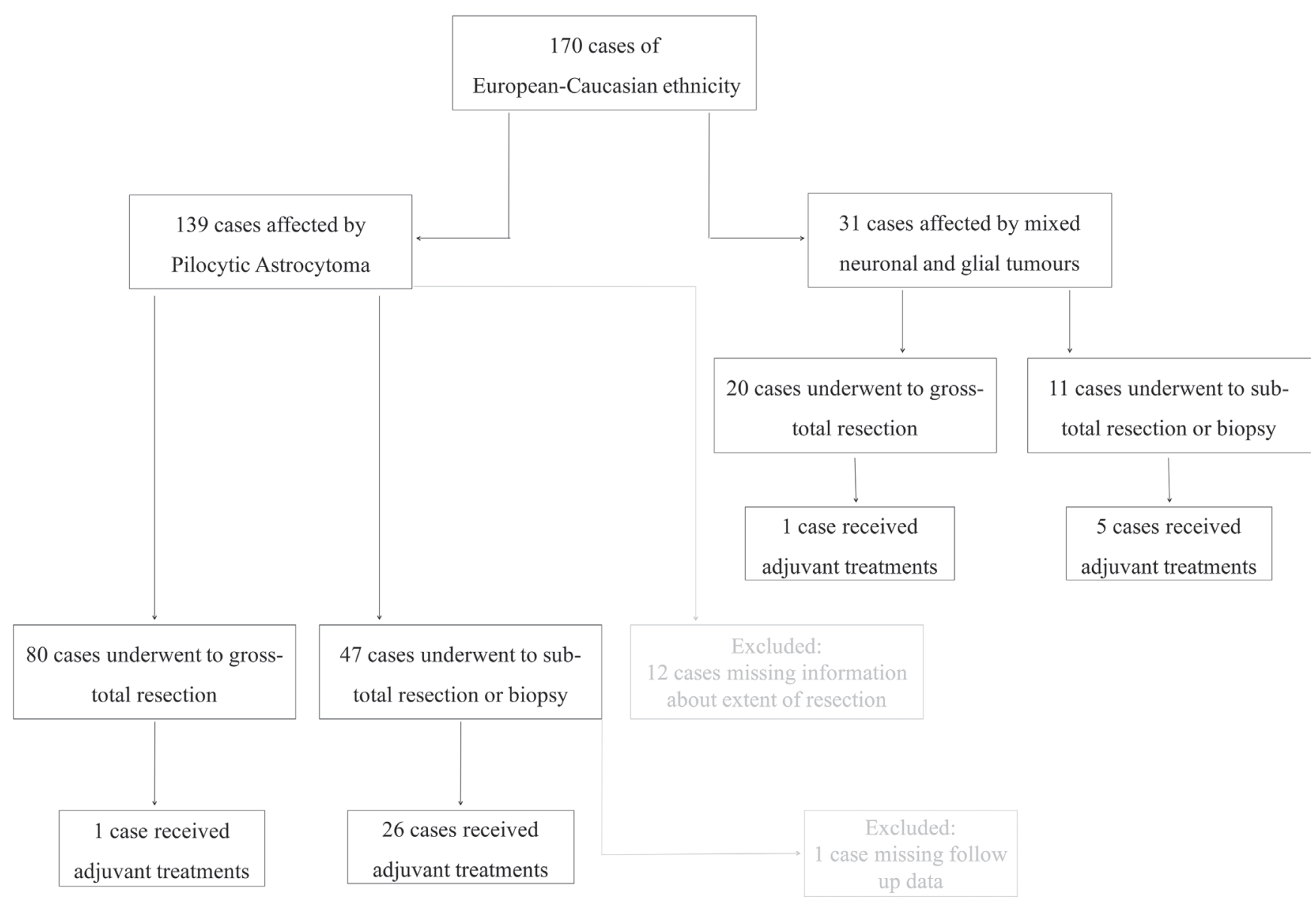

Figure 2: The flow chart of patient selection, including histological and extension of surgical resection criteria. The excluded cases by the analysis are reported in grey colour. 
Likelihood Ratio test (LR test) was used for comparisons and HR with their 95\% Confidence Intervals (95\% CIs) were calculated and reported. All statistical tests were 2 -sided, and $p$ values less than 0.05 were considered to be statistically significant. The software "Statistica" (release 9.0, StatSoft Corporation, Tulsa, OK) was used for descriptive and bivariate analyses, and Stata software, version 7 (Stata), was used for survival and multivariate analyses.

\section{ACKNOWLEDGMENTS}

The authors would like to thank all the patients' families. We also thank Camusso Raffaella and Tedeschi Luca (Photographic Service, Giannina Gaslini Institute, Genoa, Italy) for the graphic assistance in preparing the figure.

\section{CONFLICTS OF INTEREST}

The authors declare they have no conflicts of interest.

\section{Authors Contribution}

S. M.:, conceived, designed the study, data analysis and interpretation, drafted the manuscript, and corresponding author; P. N.: contributed to design the study, histopathology review, drafted and revised the manuscript; D.T.W.J.: collected and assembled data, review the manuscript; C.C.: collaborated to design the study, collected and assembled clinical and genetic data, contributed to draft the manuscript; A.P.: statistical data analysis and interpretation, collaborated to draft the manuscript; C.M., M.R., A.C, A.C: provided clinical data; collected and assembled clinical data; O.W.: performed data analysis and interpretation, review the manuscript; G.M.: collected and assembled radiological data; V.C.: collected and assembled data, review the manuscript; R.B.: performed data analysis and interpretation, review the manuscript; S.M.P.: coordinated the study design, data review and contributed to draft the manuscript ; D.F.B.: coordinated the study design, histopathology review and contributed to draft the manuscript; M.L.G.: clinical interpretation of analysis, review the manuscript; A. R.: senior researcher, conceived, designed the study, data analysis and interpretation, and drafted the manuscript.

All authors approval of the final manuscript and take responsibility for the content and interpretation of this article.

\section{FUNDING}

This work was supported by the "Associazione Italiana per la Ricerca dei Tumori Cerebrali del Bambino" (www.artuceba.org) (S. Mascelli/A. Raso), by AIRC (Italian Association for Cancer Research-Inter-Regional Grant on Pediatric Oncology) (M.L. Garrè), and by grants from Institut National du Cancer (grant INCa-DGOSInserm 6038) (D. Figarella-Branger / C. Colin).

\section{REFERENCES}

1. Imyanitov EN. Gene polymorphisms, apoptotic capacity and cancer risk. Hum Genet. 2009; 125:239-246.

2. Dasika GK, Lin SC, Zhao S, Sung P, Tomkinson A, Lee EY. DNA damage-induced cell cycle checkpoints and DNA strand break repair in development and tumorigenesis. Oncogene. 1999; 18:7883-99.

3. Pietsch EC, Humbey O, Murphy ME. Polymorphisms in the p53 pathway. Oncogene. 2006; 25:1602-1611.

4. Whibley C, Pharoah PD, Hollstein M. P53 polymorphisms: cancer implications. Nat Rev Cancer 2009; 9:95-107.

5. Dumont P, Leu JI, Della Pietra AC 3rd, George DL, Murphy M. The codon 72 polymorphic variants of p53 have markedly different apoptotic potential. Nat Genet Mar. 2003; 33:357-65.

6. El Hallani S, Ducray F, Idbaih A, Marie Y, Boisselier B, Colin C, Laigle-Donadey F, Rodéro M, Chinot O, Thillet J, Hoang-Xuan K, Delattre JY, Sanson M. TP53 codon 72 polymorphism is associated with age at onset of glioblastoma. Neurology. 2009; 72:332-6.

7. Hrstka R, Coates PJ, Vojtesek B. Polymorphisms in p53 and the p53 pathway: roles in cancer susceptibility and response to treatment. J Cell Mol Med. 2009; 13:440-453.

8. De Oliveira WR, Rady PL, Grady J, Hughes TK, Neto CF, Rivitti EA, Tyring SK. Association of p53 arginine polymorphism with skin cancer. Int J Dermat. 2004; 43:489-93.

9. Cattelani S, Ferrari-Amorotti G, Galavotti S, Defferrari R, Tanno B, Cialfi S, Vergalli J, Fragliasso V, Guerzoni C, Manzotti G, Soliera AR, Menin C, Bertorelle R, et al. The p53 codon 72 Pro/Pro genotype identifies poor-prognosis neuroblastoma patients: correlation with reduced apoptosis and enhanced senescence by the p53-72P isoform. Neoplasia 2012; 14:634-43.

10. Siddique MM, Balram C, Fiszer-Maliszewska L, Aggarwal A, Tan A, Tan P, Soo KC, Sabapathy K. Evidence for selective expression of the p53 codon 72 polymorphs: implications in cancer development. Cancer Epidemiol Biomarkers Prev. 2005; 14:2245-52.

11. Damin AP, Frazzon AP, Damin DC, Roehe A, Hermes V, Zettler C, Alexandre CO. Evidence for an association of TP53 codon 72 polymorphism with breast cancer risk. Cancer Detect Prev. 2006; 30:523-529.

12. $\mathrm{Hu} \mathrm{Y,} \mathrm{McDermott} \mathrm{MP,} \mathrm{Ahrendt} \mathrm{SA.} \mathrm{The} \mathrm{p53} \mathrm{codon} 72$ proline allele is associated with p53 gene mutations in non small cell lung cancer. Clin Cancer Res. 2005; 11:2502-2509.

13. Storey A, Thomas M, Kalita A, Harwood C, Gardiol D, Mantovani F, Breuer J, Leigh IM, Matlashewski G, Banks L. Role of a p53 polymorphism in the development of human papillomavirus associated cancer. Nature. 1998; 393:229-234. 
14. Wegman P, Stal O, Askmalm MS, Nordenskjöld B, Rutqvist LE, Wingren S. p53 polymorphic variants at codon 72 and the outcome of therapy in randomized breast cancer patients. Pharmacogenet Genomics. 2006; 16:347-351.

15. Lima-Ramos V, Pacheco-Figueiredo L, Costa S, Pardal F, Silva A, Amorim J, Lopes JM, Reis RM. TP53 codon 72 polymorphism in susceptibility, overall survival, and adjuvant therapy response of gliomas. Cancer Genet Cytogenet. 2008; 180:14-19.

16. Lambert SR, Witt H, Hovestadt V, Zucknick M, Kool M, Pearson DM. Differential expression and methylation of brain developmental genes define location-specific subsets of pilocytic astrocytoma. Acta Neuropathol. 2013; 126:291-301.

17. Faria C, Miguéns J, Antunes JL, Salgado D, Nunes S, Barroso C, Martins Mdo C, Nunes VM, Roque L. Pediatric brain tumors: genetics and clinical outcome. J Neurosurg Pediatr. 2010; 5:263-70.

18. Kaatsch P. Epidemiology of childhood cancer. Cancer Treat Rev. 2010; 36:277-85.

19. Gnekow AK, Falkenstein F, von Hornstein S, Zwiener I, Berkefeld S, Bison B, Warmuth-Metz M, Driever PH, Soerensen N, Kortmann RD, Pietsch T, Faldum A. Longterm follow-up of the multicenter, multidisciplinary treatment study HIT-LGG-1996 for low-grade glioma in children and adolescents of the German Speaking Society of Pediatric Oncology and Hematology. Neuro Oncol. 2012; 14:1265-84.

20. Louis DN, Ohgaki H, Wiestler OD, Cavenee WK, Burger PC, Jouvet A, Scheithauer BW, Kleihues P. The 2007 WHO classification of tumours of the central nervous system. Acta Neuropathol. 2007; 114:97-109.

21. Hargrave D. Paediatric high and low grade glioma: the impact of tumour biology on current and future therapy. $\mathrm{Br}$ J Neurosurg. 2009; 23:351-63.

22. Kraus JA, Felsberg J, Tonn JC, Reifenberger G, Pietsch T. Molecular genetic analysis of the TP53, PTEN, CDKN2A, EGFR, CDK4 and MDM2 tumour-associated genes in supratentorial primitive neuroectodermal tumours and glioblastomas of childhood. Neuropathol Appl Neurobiol. 2002; 28:325-33.

23. Pollack IF, Biegel J, Yates A, Hamilton R, Finkelstein S. Risk assignment in childhood brain tumors: the emerging role of molecular and biologic classification. Curr Oncol Rep. 2002; 4:114-22.

24. Olivier M, Eeles R, Hollstein M, Khan MA, Harris CC, Hainaut P. The IARC TP53 database: new online mutation analysis and recommendations to users. Hum Mutat. 2002; 19:607e14.

25. Pollack IF, Finkelstein SD, Burnham J, Holmes EJ, Hamilton RL, Yates AJ, Finlay JL, Sposto R; Children's Cancer Group. Age and TP53 Mutation Frequency in Childhood Malignant Gliomas: results in a multiinstitutional cohort. Cancer Res. 2001; 61:7404-7407.
26. Hayes VM, Dirven CM, Dam A, Verlind E, Molenaar WM, Mooij JJ, Hofstra RM, Buys CH. High frequency of TP53 mutations in juvenile pilocytic astrocytomas indicates role of TP53 in the development of these tumors. Brain Pathol. 1999; 9:463-7.

27. Broniscer A, Baker SJ, West AN, Fraser MM, Proko E, Kocak M, Dalton J, Zambetti GP, Ellison DW, Kun LE, Gajjar A, Gilbertson RJ, Fuller CE. Clinical and molecular characteristics of malignant transformation of low-grade glioma in children. J Clin Oncol. 2007; 25:682-9.

28. Patt S, Gries H, Giraldo M, Cervos-Navarro J, Martin H, Jänisch W, Brockmöller J. p53 gene mutations in human astrocytic brain tumors including pilocytic astrocytomas. Hum Pathol. 1996; 27:586-9.

29. Parhar P, Ezer R, Shao Y, Allen JC, Miller DC, Newcomb EW. Possible association of p53 codon 72 polymorphism with susceptibility to adult and pediatric high-grade astrocytomas. Brain Res Mol Brain Res. 2005; 137:98-103.

30. Idbaih A, Boisselier B, Marie Y, El Hallani S, Sanson M, Crinière E, Rodero $M$, Carpentier $C$, Paris S, LaigleDonadey F, Ducray F, Hoang-Xuan K, Delattre JY. TP53 codon 72 polymorphism, $\mathrm{p} 53$ expression, and $1 \mathrm{p} / 19 \mathrm{q}$ status in oligodendroglial tumors. Cancer Genet Cytogenet. 2007; 177:103-107.

31. Petitjean A, Achatz MI, Borresen-Dale AL, Hainaut P, Olivier M. TP53 mutations in human cancers: functional selection and impact on cancer prognosis and outcomes. Oncogene. 2007; 26:2157-65.

32. Francisco G, Menezes PR, Eluf-Neto J, Chammas R. Arg72Pro TP53 polymorphism and cancer susceptibility: a comprehensive meta-analysis of 302 case-control studies. Int J Cancer. 2011; 129:920-30.

33. Shi M, Huang R, Pei C, Jia X, Jiang C, Ren H. TP53 codon 72 polymorphism and glioma risk: a meta-analysis. Oncol Lett. 2012; 3:599-606.

34. Shen H, Solari A, Wang X, Zhang Z, Xu Y, Wang L, Hu X, Guo J, Wei Q. P53 codon 72 polymorphism and risk of gastric cancer in a Chinese population. Oncol Rep. 2004; 11:1115-20.

35. Beckman G, Birgander R, Själander A, Saha N, Holmberg PA, Kivelä A, Beckman L. Is p53 polymorphism maintained by natural selection? Hum Hered. 1994; 44:266-70.

36. Bergamaschi D, Gasco M, Hiller L, Sullivan A, Syed N, Trigiante G, Yulug I, Merlano M, Numico G, Comino A, Attard M, Reelfs O, Gusterson B, et al. p53 polymorphism influences response in cancer chemotherapy via modulation of p73-dependent apoptosis. Cancer Cell. 2003; 3:387-402.

37. Jacob K, Quang-Khuong DA, Jones DT, Witt H, Lambert S, Albrecht S, Witt O, Vezina C, Shirinian M, Faury D, Garami M, Hauser P, Klekner A, et al. Genetic aberrations leading to MAPK pathway activation mediate oncogene- 
induced senescence in sporadic pilocytic astrocytomas. Clin Cancer Res. 2011; 17:4650-60.

38. Walker D, Gnekow A, Perilongo G, Zanetti I. Vincristine (VCR) carboplatin (CBDCA) in hypothalamic-chiasmatic glioma (HCG): a report of the International Consortium on Low Grade Glioma (ICLGG) [abstract]. Med Ped Oncol. 2002; 39:229.

39. Jones DT, Hutter B, Jäger N, Korshunov A, Kool M, Warnatz HJ, Zichner T, Lambert SR, Ryzhova M, Quang DA, Fontebasso AM, Stütz AM, Hutter S, et al. Recurrent somatic alterations of FGFR1 and NTRK2 in pilocytic astrocytoma. Nat Genet. 2013; 45:927-32.

40. Chappé C, Padovani L, Scavarda D, Forest F, NanniMetellus I, Loundou A, Mercurio S, Fina F, Lena G, Colin C, Figarella-Branger D. Dysembryoplastic neuroepithelial tumors share with pleomorphic xanthoastrocytomas and gangliogliomas BRAF(V600E) mutation and expression. Brain Pathol. 2013; 23:574-83.

41. Mascelli S, Barla A, Raso A, Mosci S, Nozza P, Biassoni R, Morana G, Huber M, Mircean C, Fasulo D, Noy K, Wittemberg G, Pignatelli S, et al. Molecular fingerprinting reflects different histotypes and brain region in low grade gliomas. BMC Cancer. 2013; 13:387.

42. Mascelli S, Raso A, Biassoni R, Severino M, Sak K, Joost K, Milanaccio C, Barra S, Grillo-Ruggieri F, Vanni I, Consales A, Cama A, Capra V, et al. Analysis of NADP+dependent isocitrate dehydrogenase-1/2 gene mutations in pediatric brain tumors: report of a secondary anaplastic astrocytoma carrying the IDH1 mutation. J Neurooncol. 2012; 109:477-84. 